\title{
An experimental study of the effect of back rake angle in rock cutting
}

\author{
Iman Rostamsowlat ${ }^{\mathrm{a}, \mathrm{b}, *}$, Thomas Richard ${ }^{\mathrm{c}}$, Brian Evans ${ }^{\mathrm{a}}$ \\ ${ }^{a}$ Deep Exploration Technologies CRC, Department of Petroleum Engineering, Curtin \\ University, Australia \\ ${ }^{b}$ Rock Mechanics 85 Drilling Mechanics Groups, CSIRO Energy, Perth, Australia \\ ${ }^{c}$ Epslog SA, 69 Jean Street, Hamilton Hill, 6163 WA, Australia
}

\begin{abstract}
The objective of this paper is to investigate the influence of the rake angle on the magnitude of the intrinsic specific energy and the inclination of the force acting on the cutting face of a Polycrystalline Diamond Compact (PDC) sharp cutter while tracing a groove on the surface of a rock sample. An extensive and comprehensive set of cutting experiments are performed on a wide range of quarry rock samples using a state of the art rock cutting equipment (Wombat). The results conform with the previous studies by other researchers; the intrinsic specific energy is in good agreement with the uni-axial compressive strength of the rock samples when the cutter is positioned at back rake angles between $5^{\circ}$ and $20^{\circ}$. New results on a few rock samples were also obtained by performing novel experimental tests at very large rake angles $\left(\theta>70^{\circ}\right)$ as well as negative rake angles, showing that the intrinsic specific energy increases dramatically once the back rake angle exceeds $75^{\circ}$. Results also indicate that the decrease of the apparent interfacial friction angle with increasing back rake angle seems to follow a "universal trend" weakly dependent on the rock sample.

Keywords:

Rock cutting, Back rake angle, Intrinsic specific energy, Interfacial friction angle, PDC cutter
\end{abstract}

\footnotetext{
${ }^{*}$ Corresponding author:

Email address: iman.rostamsowlat@gmail.com, iman.rostamsowlat@postgrad.curtin.edu.au (Iman Rostamsowlat)

Preprint submitted to Journal of $E^{A} T_{E} X$ Templates

January 18, 2018
} 


\section{Introduction}

Polycrystalline Diamond Compact (PDC) bits have been used in the petroleum drilling industry since 1973. Unlike tricone bits, which indent the rock with a crushing force, PDC bit cutters machine out the rock surface and cause rock

5 failure by a shearing action. Rock cutting is one of the most important processes involved in the mechanical excavation and drilling of rock, which have both been research topics of particular interest in the areas of civil, mining and petroleum engineering over the past decades. A drill bit is a collection of cutting elements (cutters) whose rake angles can vary from cutter to cutter [1 4].

It is generally accepted in the literature [5-10] that the force acting on a single cutter is governed by the coexistence of two independent processes: $(i)$ a "frictional contact" process mobilised across the wear flat, and (ii) a "pure cutting" action in front of the cutting face. This study focuses on the pure cutting process where the term "pure" means that all the energy is devoted to remove the rock material and no energy is dissipated by the frictional contact process.

Rock cutting can be characterized by two main failure modes (depending on the depth of cut) that take place ahead of the cutting face: $(i)$ a ductile regime (with depth of cut typically less than $1 \mathrm{~mm}$ [11]) which is characterized by the de-cohesion of the constitutive matrix and grains of the rock with grains and powder accumulating progressively ahead of the cutter and (ii) a brittle regime (at larger depth of cut) which is associated with the propagation of macroscopic cracks at the tip of the cutting tool [11-15. In the case of ductile regime, work performed by the cutter is proportional to the volume of rock being removed, 25 which leads to a linear relationship between the cutting force and the crosssectional area of the groove traced by the cutter [7, 12. The two cutting force components $F_{c n}$ and $F_{c s}$, normal (subscript $n$ ) and parallel (subscript $s$ ) to the velocity vector $\boldsymbol{v}$ (see Fig. 1), respectively, can be written as: 

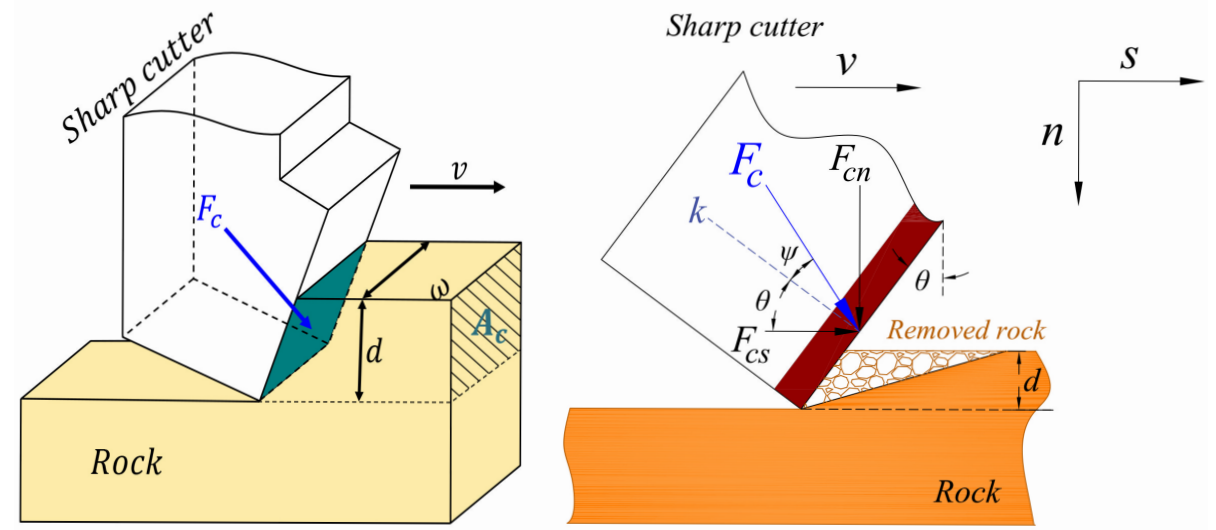

Figure 1: Schematic of force components acting on a sharp cutter.

$$
\left\{\begin{array}{c}
F_{c n}=\zeta \varepsilon A_{c} \\
F_{c s}=\varepsilon A_{c}
\end{array}\right.
$$

Here, $\varepsilon$ is the intrinsic specific energy (defined as the minimum energy to remove a unit volume of the rock with the unit of stress $M P a$ [16]) which increases with increasing back rake angle $(\theta)$ but correlates very well with the uni-axial compressive strength $(q)$ of the rocks for rectangular cutter (for $\omega \simeq$ $10-20 \mathrm{~mm}$ where $\omega$ is the width of cutter) when the back rake angle $(\theta)$ is in the range of $10^{\circ}$ to $20^{\circ}[11,12,17,21$. The back rake angle or $\theta$ is defined as the angle between the normal to the cutting surface $(k)$ and the velocity vector and $A_{c}$ is the cross-sectional area of the groove traced by the cutter $\left(A_{c}=\omega \times d\right.$ for a rectangular shaped cutter where $d$ is the depth of cut). The number $\zeta$ is given by:

$$
\zeta=\tan (\theta+\psi)
$$

where $\psi$ is the interfacial friction angle which is found independent of the depth

40 of cut for a given back rake angle. However, experimental observations [12, 22, suggest that the interfacial friction angle is predominantly affected by the back 
rake angle; an increase in the back rake angle leads to a decrease of interfacial friction angle. Results suggest that the failed materials mostly flow upward at small rake angle but as the back rake angle increases, backward flow of material increases at the expense of the upward flow due to the presence of a zone of dead material (or build-up edge BUE) at the cutting edge, leading to an overall rotation of the resulting cutting force with respect to the normal to the cutter. Although research efforts 21-24] have been devoted to study the cutting response of sharp and blunt cutters, to the best knowledge of authors, no work has been dedicated to capture the evolution of the cutting response of a sharp cutter at negative back rake angles and as the back rake angles approaches $90^{\circ}$.

In the present paper, we present, analyze and discuss the results of tests carried out with a sharp cutter at different back rake angles but also on a wide range of sedimentary rock samples with the intention of exploring the effect of rock material on the relation between the interfacial friction angle and the back rake angle. Furthermore, on a few rock samples, the back rake angle was varied from a negative value (cutter inclined backward with respect to the direction of cutting) to the highest possible forward inclination allowed by the equipment, up to nearly $85^{\circ}$, with the intention of capturing the transition from a cutting (uncontained failure) to a contact (contained failure) process as the cutter forward inclination increases. For this purpose, an extensive series of laboratory cutting experiments were conducted on thirteen different rock samples (clastics and carbonates) on a state of the art rock cutting laboratory equipment using a tailored designed cutter holder with adjustable rake angle.

\section{${ }_{65}$ 2. Experimental setup}

\subsection{Scratching device (The Wombat)}

The "Wombat" machine developed by EPSLOG Engineering SA, shown in Fig. 2 , is designed to scratch rock samples under constant depth of cut $(d)$. The cutter moves at a constant horizontal velocity $(\boldsymbol{v}=4 \mathrm{~mm} / \mathrm{s})$ while the appara- 
tus records separately the magnitudes of the normal $\left(F_{n}\right)$ and tangential $\left(F_{s}\right)$ components of the total force acting on the cutter with a precision of $1 \mathrm{~N}$ over a range of 0 to $\pm 4000 \mathrm{~N}$.

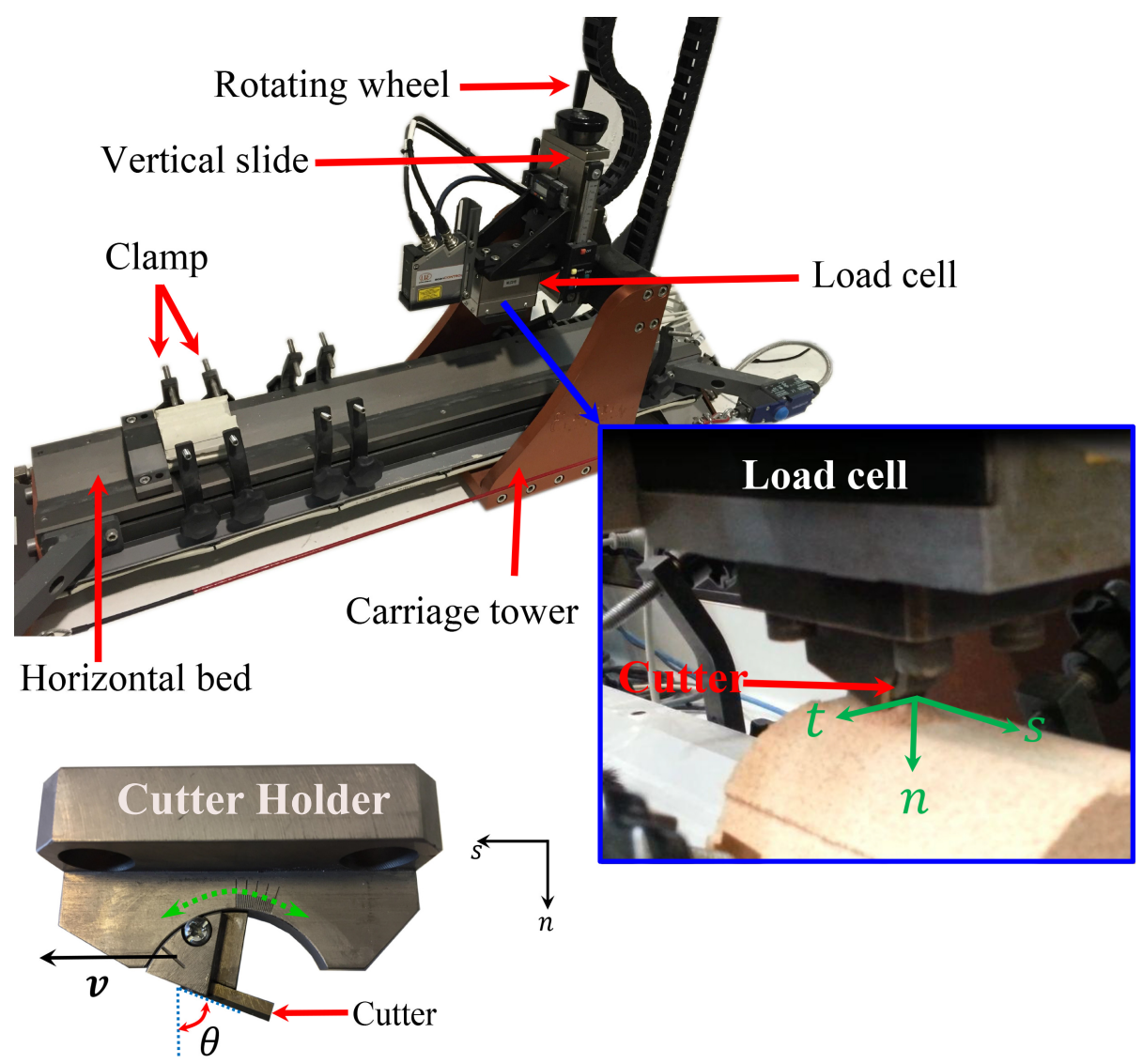

Figure 2: Wombat parts and cutter holder.

A ball screw via a stepper motor gear box configuration drives the horizontal travelling block which supports a frame hosting a vertical slide on which a load sensor is mounted. A rotating wheel is used to travel the vertical slide and the sensor, up and down to precisely adjust the depth of cut. A digital micrometer displays readout of the position of the travelling mechanism. Locking screws are used to lock the slide in position once the depth of cut is set. A Windows- 
based-software (GUI) written in Matlab allows the user to select the cutting velocity and the test length.

A cutter holder was used to impose the back rake angle (see Fig. 2). An image processing software (ImageJ) was used to highlight the edges of the cutter and then imported into the AutoCad 2015 to measure the back rake angle precisely. The step by step procedure is detailed in Ref. [25].

The slant of the cutter or the back rake angle $(\theta)$, is the inclination of the cutter in reference system of axes $(n-s)$ where the vector $s$ is co-linear to the velocity vector $(\boldsymbol{v})$, see Fig. 1. The back rake angle is defined as the angle between the velocity vector $(\boldsymbol{v})$ and the normal $\boldsymbol{k}$ to the cutting face of the cutter.

\subsection{Cutters}

This study is concerned with PDC sharp cutters which are made of thin layer of polycrystalline diamond laid down on a carbide tungsten base. The work is restricted to rectangular shaped cutters of width $\omega=10 \mathrm{~mm}$. Apart from tests carried out at negative rake angles, cutting tests were performed with the standard PDC sharp cutter. In the case of negative angles, a PDC sharp cutter was machined so its relief surface would not drag against the rock. These cutters are nominally sharp cutters and the cutting edge of each cutter is regularly monitored using a high resolution optical microscope (model AxioScope Imager A1). The drawings and pictures of the cutters used for the current study are presented in Appendix A

\subsection{Rock materials}

The tests were conducted on thirteen different quarry rocks, three limestones (Tuffeau, Savonnieres and Indiana) and ten sandstones (Mountain Gold, Castlegate, Bentheimer, Boise, Berea I and Berea II, Berea Sister Gray, Buff Berea, Berea Upper Gray and Carbon Tan) with different porosities, apparent densities and uni-axial compressive strengths. Table 1 lists some of the mechanical and 
petro-physical properties of the rock materials.

Table 1: Mechanical and petro-physical properties of rock materials used for cutting tests [25].

\begin{tabular}{|c|c|c|c|c|c|c|c|}
\hline $\begin{array}{c}\text { Rock } \\
\text { type }\end{array}$ & $\begin{array}{l}\text { Rock } \\
\text { name }\end{array}$ & $\begin{array}{c}q \\
(M P a)\end{array}$ & $\begin{array}{c}\Phi_{\text {Dry }} \\
(\%)\end{array}$ & $\begin{array}{c}\rho_{\text {Dry }} \\
\left(\mathrm{kg} / \mathrm{m}^{3}\right)\end{array}$ & $\begin{array}{c}K \\
(m D)\end{array}$ & $\begin{array}{c}E \\
(G P a)\end{array}$ & $\nu$ \\
\hline \multirow{3}{*}{ 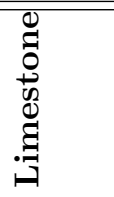 } & Tuffeau & 8.51 & 41.49 & 1360 & 39.07 & 1.70 & 0.24 \\
\hline & Indiana & 30.20 & 16 & 2290 & 4 & 16.10 & 0.10 \\
\hline & Savonnieres & 19.58 & 32.23 & 1880 & 25.15 & 12.23 & 0.21 \\
\hline \multirow{12}{*}{ 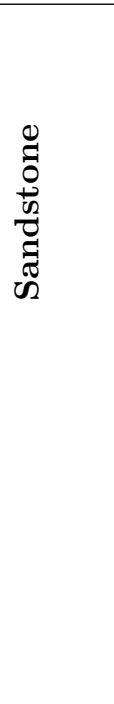 } & Castlegate & 15.03 & 26 & 1970 & 750 & 3.73 & 0.63 \\
\hline & Mountain Gold & 34 & 15.70 & 2220 & 2.09 & 8.10 & 0.20 \\
\hline & Bentheimer & 49.13 & 24 & 2320 & 2.30 & 12.82 & 0.26 \\
\hline & Boise & 23.73 & 28 & 1830 & 1.70 & 8.60 & 0.31 \\
\hline & Berea I & 38.95 & 21 & 2090 & 496.39 & 11.80 & 0.25 \\
\hline & Berea II & 47.10 & 23 & 2320 & 260.51 & 13.04 & 0.43 \\
\hline & Buff Berea & 35.54 & 22 & 2008 & 150 & 9.32 & 0.23 \\
\hline & Berea & 50.40 & 21 & 2140 & 80 & 11.90 & 0.20 \\
\hline & (Sister Gray) & & & & & & \\
\hline & Berea & 44.80 & 19.46 & 2170 & 115 & 13.20 & 0.40 \\
\hline & (Upper Gray) & & & & & & \\
\hline & Carbon Tan & 56.2 & 15 & 2220 & 11 & 10.2 & 0.38 \\
\hline
\end{tabular}

$q$ : Uni-axial compressive strength, $\Phi_{D r y}$ : Dry porosity, $\rho_{D r y}$ : Dry density, $K$ : permeability, $E$ : Young's modulus, $\nu$ : Poisson's ratio

A compression test machine (manufactured by Wykeham Farrance) was used to measure the uni-axial compressive strength $(q)$, Young's modulus $(E)$ and Poisson's ratio $(\nu)$ of the rock samples used in this research. This machine is a displacement controlled machine which comprises of the main mechanical parts: a load frame, a load cell, two strain gauges for radial strain $\left(\epsilon_{r}\right)$ which have been manufactured by CSIRO, two compression platens, a control system, a gear box and two LVDTs (Linear variable displacement transducers) for axial 115 strain $\left(\epsilon_{a}\right)$. The rock samples were cut into cylindrical shapes with length 
over diameter ratio of approximately 2.2. The rock sample was set up in the compression test machine with transducers in place to measure sample axial and radial deformations and axial load. Each core plug was tested unsaturated. Each sample was axially loaded under a constant average axial strain rate $0.5 \%$ giving a loading rate of $0.259 \mathrm{~mm} / \mathrm{min}$ for both Bentheimer and Boise and 0.014 $\mathrm{mm} / \mathrm{min}$ for all other rocks until the samples failed. The Young's modulus $(E)$ and Poisson's ratio $(\nu)$ were determined from the tangential slope of the curve of deviatoric stress versus average axial strain and the tangential slope of the curve of average radial strain versus average axial strain between $40 \%$ and $60 \%$ of the maximum deviatoric stress, respectively.

To measure the grain (or particle) size of the rock samples, these rock samples were crushed very gently in a mortar with a plastic pestle. An Ultrasonic Bath Cleaner was also used to ensure the grains were completely separated from each other. A Mastersizer 3000 laser diffraction particle size analyzer was used 130 to measure the grain (particle) sizes. This machine can be used for both wet and dry particles by measuring the intensity of the light scattered as a laser beam passes through a dispersed particulate sample. The grain diameters corresponding to $10 \%, 50 \%$, and $90 \%$ finer (from the cumulative grain-size distributions) are listed in Table 2 
Table 2: Grain size distribution diameters.

\begin{tabular}{|l|cccc|}
\hline \multicolumn{1}{|c}{ Rock type } & Rock name & $D_{10}(\mu \mathrm{m})$ & $D_{50}(\mu \mathrm{m})$ & $D_{90}(\mu \mathrm{m})$ \\
\hline \hline \multirow{3}{*}{ Limestone } & Tuffeau & 24 & 181 & 533 \\
& Indiana & 9 & 515 & 1070 \\
& Savonnieres & 3 & 95 & 466 \\
\hline \multirow{5}{*}{ Sandstone } & Castlegate & 8 & 13 & 345 \\
& Mountain Gold & 8 & 401 & 792 \\
& Bentheimer & 3 & 94 & 447 \\
& Boise & 70 & 460 & 750 \\
& Berea I & 93 & 197 & 346 \\
& Berea II & 6 & 168 & 323 \\
& Buff Berea & 8 & 214 & 380 \\
& Berea sister Gray & 27 & 162 & 313 \\
& Berea Upper Gray & 31 & 155 & 312 \\
& Carbon Tan & 102 & 186 & 325 \\
\hline
\end{tabular}

$D_{10}$ is the diameter at which $10 \%$ of a sample's mass is comprised of smaller particles.

$D_{50}$ is the diameter at which $50 \%$ of a sample's mass is comprised of smaller particles.

$D_{90}$ is the diameter at which $90 \%$ of a sample's mass is comprised of smaller particles.

\subsection{Experimental procedure}

The first step consists of a visual evaluation of the sample to assess its level of inhomogeneity. It involves identifying the level of fracturing or layering of the rock specimen to isolate weak joints which can result in splitting of the specimen especially if cut is conducted orthogonal to the direction of fracturing. The second step involves the clamping of the specimen on the machine. One or several primary cuts are required prior to any test series in order to flatten the rock surface and to provide a horizontal groove surface of width equal to the cutter width over the length of test that is envisaged. The first depth of cut is roughly estimated (typically around $0.15 \mathrm{~mm}$ ) by positioning the cutter tip at a given location below the highest point of the sample surface. Subsequent depths of cut are adjusted relative to the previous groove level. From one test 
to another, the depth of cut is adjusted relative to the prior groove. Practically, the micrometer is reset to zero after the depth of cut has been adjusted and before the test is run. Note that after carrying out a test, both the rock and cutter surfaces are cleaned with a brush. All the cutting tests in this research were carried out in the ductile regime of failure mode.

\section{Experimental results and discussion}

For a given back rake angle $(\theta)$, successive tests were carried out in the same groove with increasing depth of cut. As the back rake angle increases, the range of depth of cut decreases due to practical limitations. The depth of cut $(d)$ is simply limited by the projected height of the cutter $(d<h \cos \theta)$, see Fig. 3. Another limitation comes from the groove cumulative depth; past a critical groove depth, the edge of the holder touches the edge of the groove affecting the recording. Table 3 summarizes the range of depths of cut covered for each back rake angle.

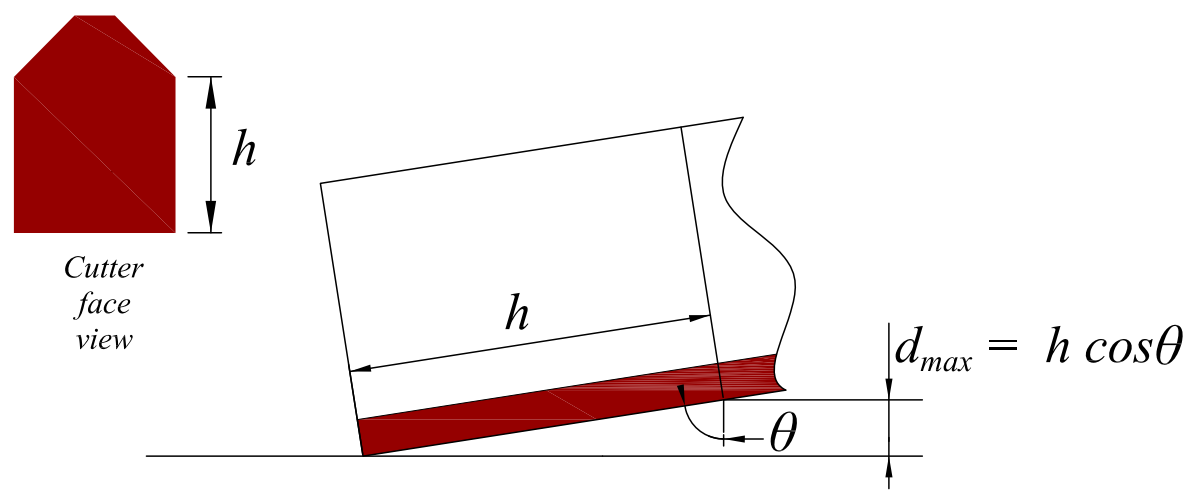

Cutter side view

Figure 3: Maximum possible depth of cut as function of cutter back rake angle. 
Table 3: Practical range of depth of cut for given back rake angle.

\begin{tabular}{cc|}
\hline Back rake angle $\theta$ & Ranges of depth of cut \\
\hline \hline$-10^{\circ}$ & $0.10 \mathrm{~mm}-0.40 \mathrm{~mm}$ \\
$15^{\circ}$ & $0.10 \mathrm{~mm}-0.70 \mathrm{~mm}$ \\
$30^{\circ}$ & $0.10 \mathrm{~mm}-0.70 \mathrm{~mm}$ \\
$45^{\circ}$ & $0.10 \mathrm{~mm}-0.50 \mathrm{~mm}$ \\
$60^{\circ}$ & $0.10 \mathrm{~mm}-0.50 \mathrm{~mm}$ \\
$70.50^{\circ}$ & $0.10 \mathrm{~mm}-0.48 \mathrm{~mm}$ \\
$82.50^{\circ}$ & $0.09 \mathrm{~mm}-0.30 \mathrm{~mm}$ \\
\hline
\end{tabular}

The intrinsic specific energy is readily derived from best linear fit carried out on the pairs $F_{c s}-A_{c}$. The number $\zeta$ is also obtained from best linear fit conducted on the set of data points $\left(F_{c n}-F_{c s}\right)$.

\subsection{Cutting responses at $0^{\circ} \leq \theta \leq 70^{\circ}$}

Results of the tests are shown in Fig. 4 to Fig. 7 and confirm results obtained by Richard [12] and Richard \& Coudyzer [22], but extend the results over a larger selection of rock materials and a larger range of back rake angles. The evolution of the intrinsic specific energy scaled by the uni-axial compressive strength $\left(\frac{\varepsilon}{q}\right)$ shown in Fig. 4 clearly shows that the intrinsic specific energy $(\varepsilon)$ is very close to the uni-axial strength of the rock $(q)$ when the back rake angle ranges from $5^{\circ}$ to $20^{\circ}$, see Table 4 This result confirms previous findings by other researchers [11, 20, see Fig. 5 . 


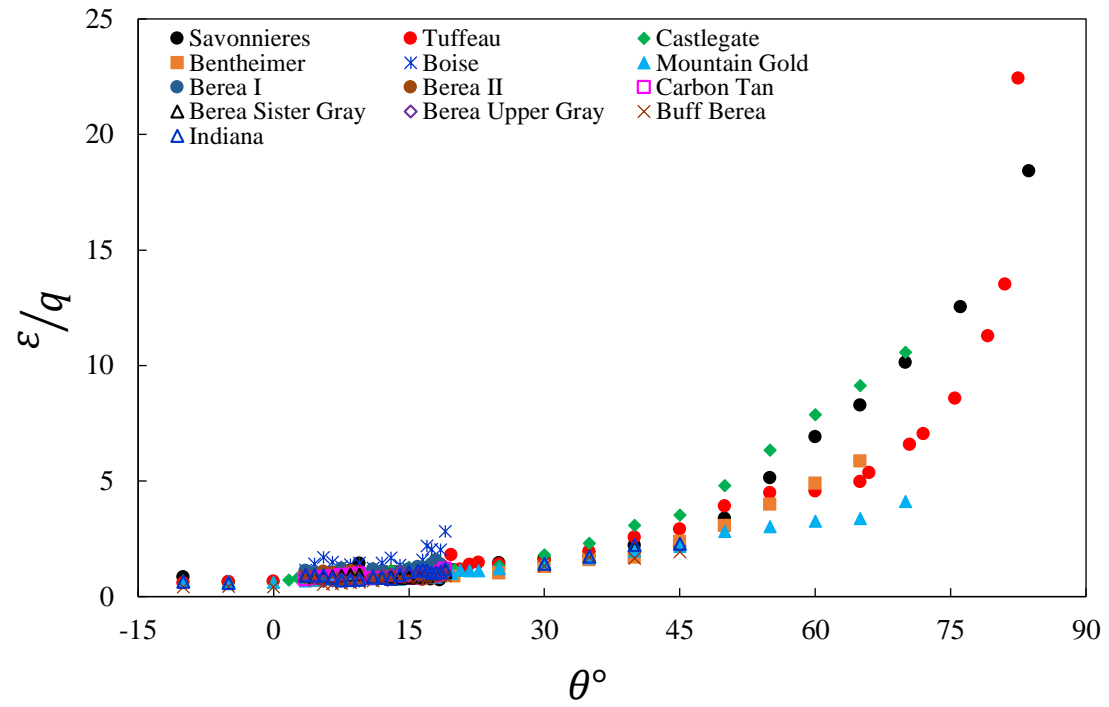

Figure 4: Scaled intrinsic specific energy $\left(\frac{\varepsilon}{q}\right)$ at different back rake angles $(\theta)$. Tests performed with PDC sharp cutter.

Table 4: Correlation between the intrinsic specific energy $(\varepsilon)$ from cutting test carried out at a 15 degree back rake angle and the uni-axial compressive strength $(q)$.

\begin{tabular}{|c|c|c|c|}
\hline Rock name & $\psi_{15^{\circ}}$ & $\varepsilon_{15^{\circ}}(\mathbf{M P a})$ & $q$ (MPa) \\
\hline Tuffeau & $13.83^{\circ}$ & 8.42 & 8.51 \\
\hline Indiana & $27.92^{\circ}$ & 32.35 & 30.20 \\
\hline Savonnieres & $12.63^{\circ}$ & 20.10 & 19.58 \\
\hline Castlegate & $15.11^{\circ}$ & 15.85 & 15.03 \\
\hline Mountain Gold & $13.26^{\circ}$ & 30.64 & 34 \\
\hline Bentheimer & $15.75^{\circ}$ & 46.42 & 49.13 \\
\hline Boise & $15.73^{\circ}$ & 28.12 & 23.73 \\
\hline Berea I & $15.54^{\circ}$ & 43.63 & 38.95 \\
\hline Berea II & $14.68^{\circ}$ & 41.79 & 47.10 \\
\hline Buff Berea & $12.10^{\circ}$ & 29.72 & 35.54 \\
\hline Berea Sister Gray & $14.24^{\circ}$ & 42.36 & 50.40 \\
\hline Berea Upper Gray & $16.79^{\circ}$ & 44.73 & 44.80 \\
\hline Carbon Tan & $14.40^{\circ}$ & 50.52 & 56.20 \\
\hline
\end{tabular}




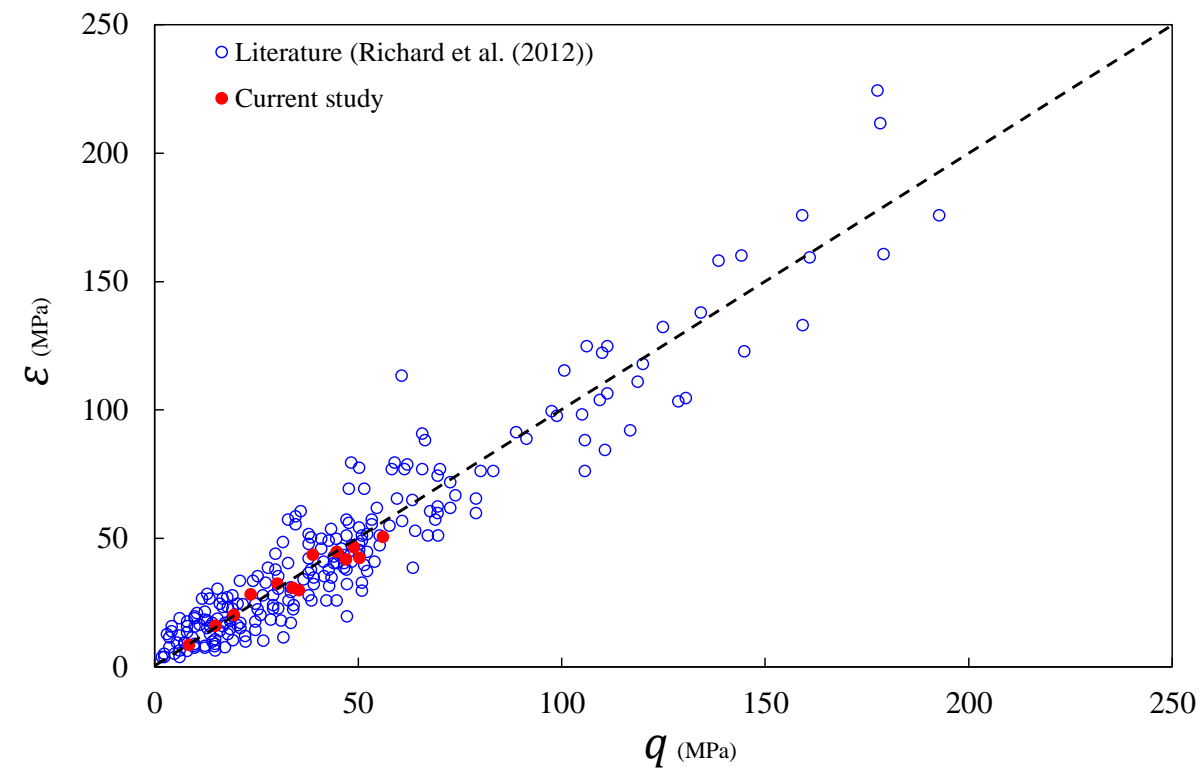

Figure 5: Correlation between the intrinsic specific energy $(\varepsilon)$ and the uni-axial compressive strength $(q)$. Current study against the literature.

Although there is some dispersion in the data, in particular at small angles, the evolution of interfacial friction angle $(\psi)$ with the back rake angle follows a relatively "universal trend" only weakly dependent on the rock material (Fig. 6). These results indicate that $\psi$ is not controlled by a uniform frictional process between the failed rock and the cutting face. The interpretation proposed by Richard [12] invokes the presence of a build-up edge (BUE) formed at the bottom of the cutting face, which results in a division of the flow of failed rock into an upward and a backward flow, as schematically shown in Fig 8. Increase of the back rake angle is accompanied by an increase of the backward flow at the expense of the upward flow, resulting in a decrease of the apparent interfacial friction angle, $\psi$. 


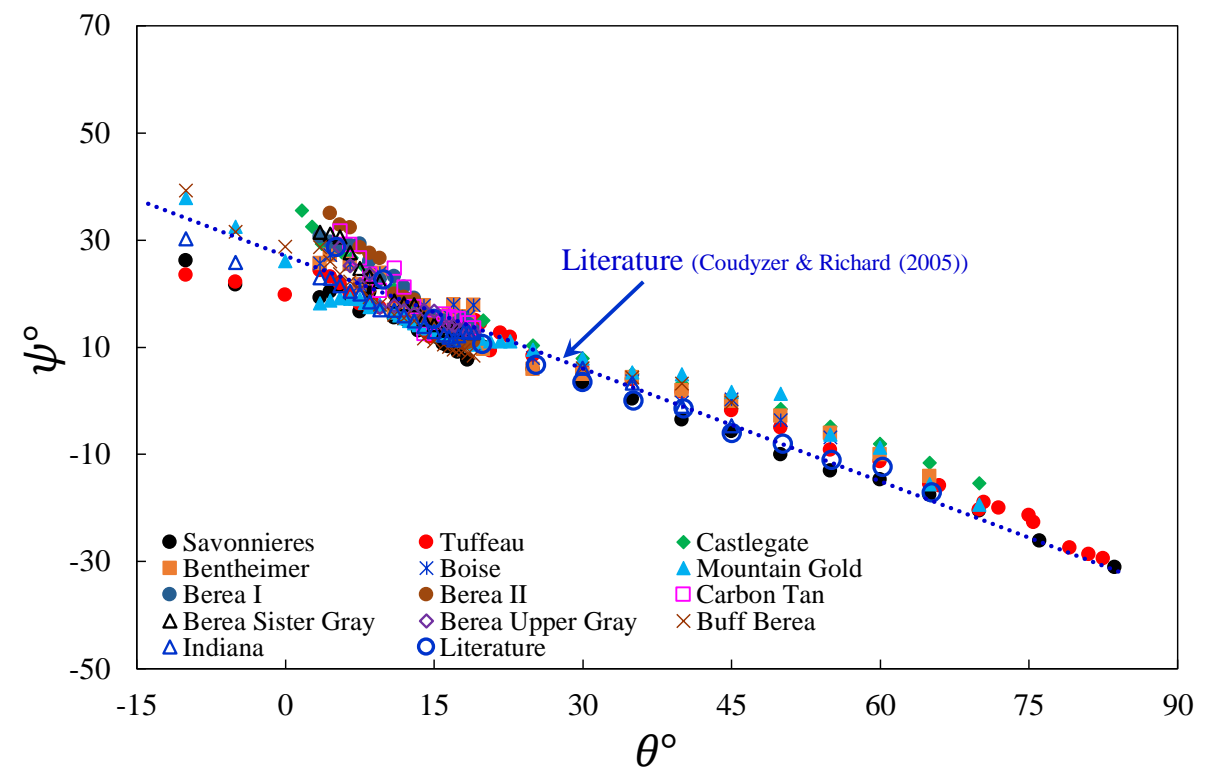

Figure 6: Evolution of interfacial friction angle $(\psi)$ with the back rake angle $(\theta)$.

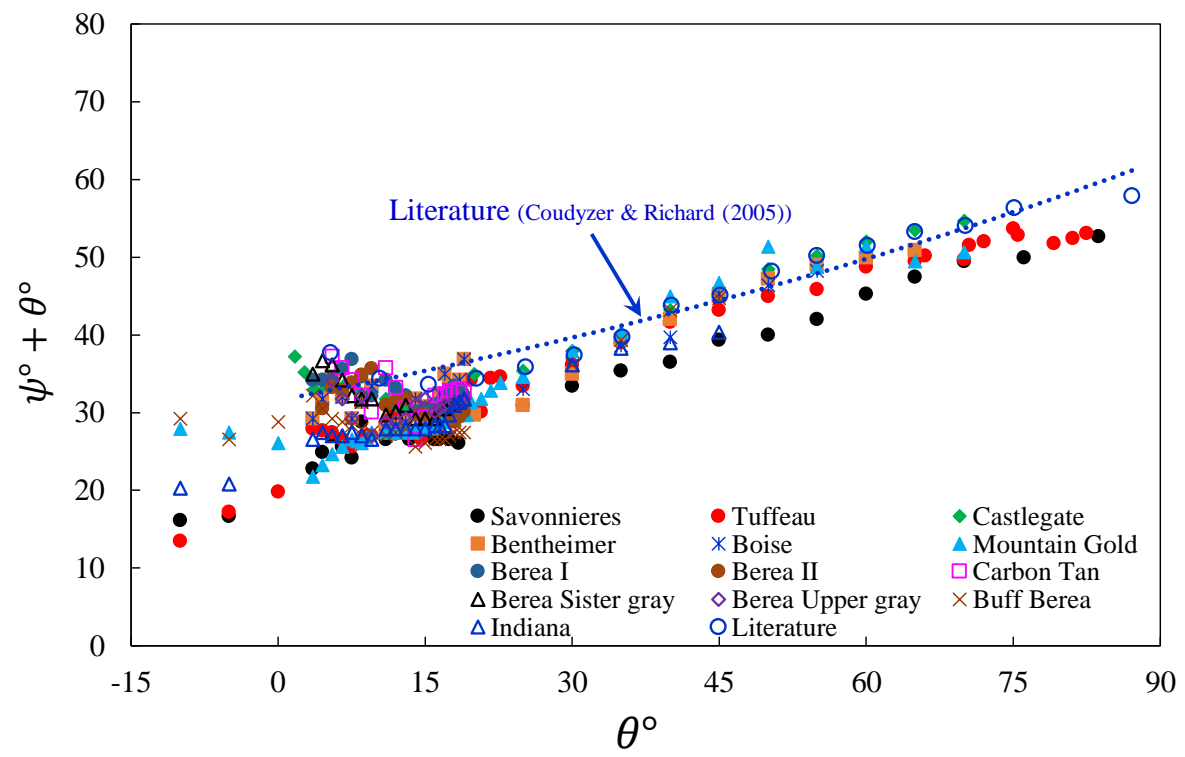

Figure 7: Variation of total cutting force inclination angle $(\psi+\theta)$ with back rake angle $(\theta)$. 
The observed dispersion in the interfacial friction angle at small angles is associated to materials characterized by a fine grain structure and therefore could be attributed to some of the fine crushed particles being trapped within the asperities (roughness) of the cutter edge, acting as a small wear flat surface at the cutter edge. Since experiments at shallow back rake angle have been carried out over a limited range of depth of cut, it is likely that the presence of this apparent contact surface at the edge affected the estimate of the interfacial friction angle 26 and possibly the estimate of the intrinsic specific energy which could explain some of the dispersion observed in Fig. 9 for $5^{\circ}<\theta<15^{\circ}$.
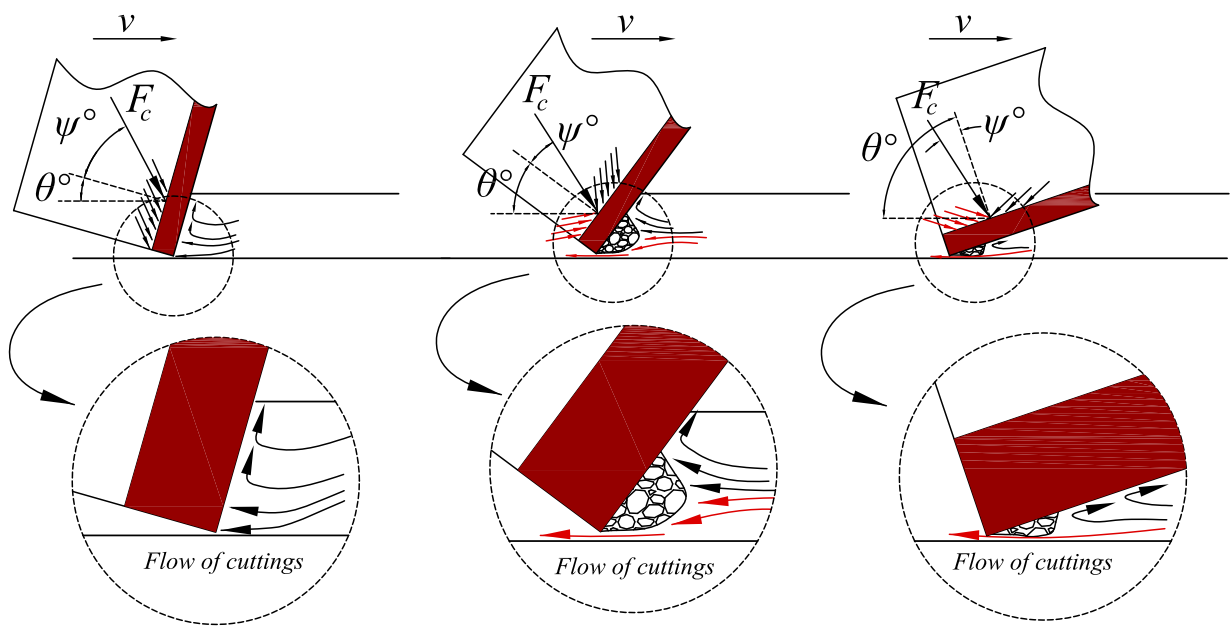

Figure 8: Flow of the crushed material (cuttings) at different back rake angles.

\subsection{Cutting response at $\theta<0^{\circ}$ and $\theta>70^{\circ}$}

In comparison to earlier work [12, 22], the present results cover a wider range of back rake angle and in particular cover negative back rake angles but also angles beyond $70^{\circ}$. The intrinsic specific energies at negative back rake is found smaller than (nearly half) the ones measured at shallow positive angles $\left(5^{\circ}\right.$ to $20^{\circ}$ ), see Fig. 9. Experimental evidence (occurrence of small fragments or chips, 
sound, force signal) indicates that susceptibility to brittle failure increases as the back rake is lowered, which in turn lowers the estimated intrinsic specific energy [27].

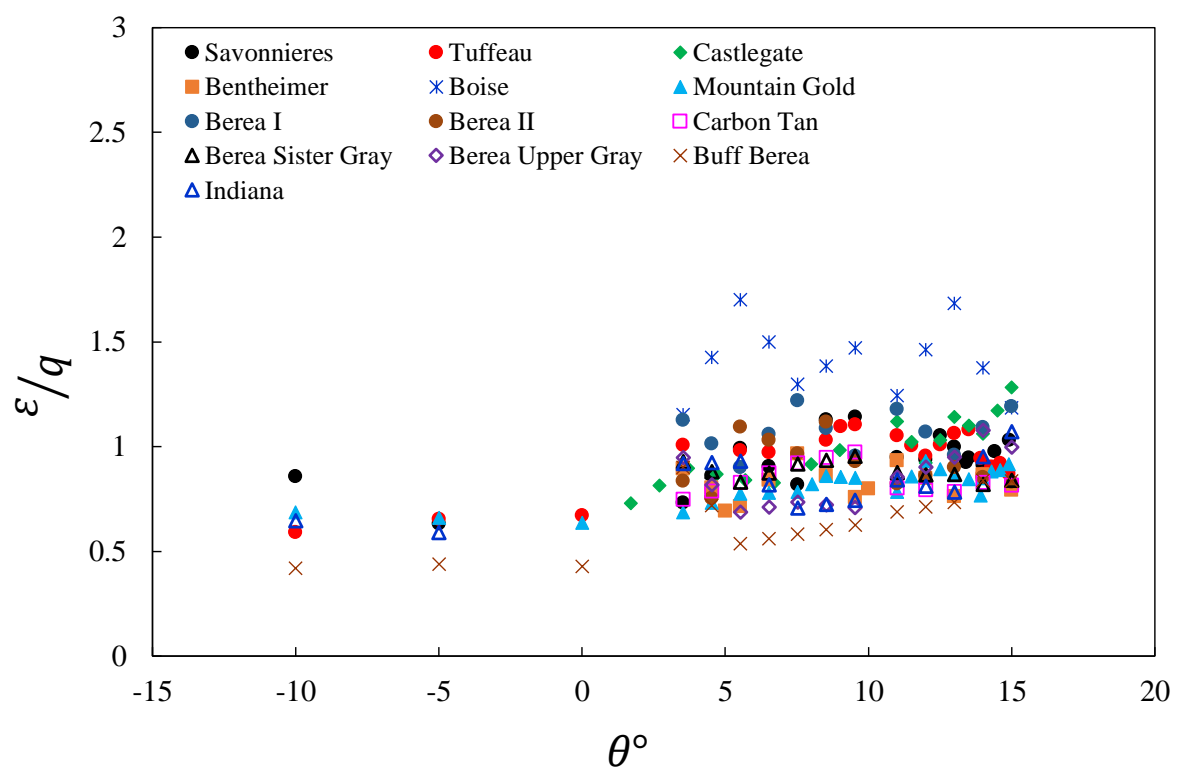

Figure 9: Scaled intrinsic specific energy $\left(\frac{\varepsilon}{q}\right)$ versus back rake angle $(\theta)$ for $-10^{\circ} \leq \theta \leq 15^{\circ}$.

At large back rake angles (beyond 70 degrees), the intrinsic specific en$\operatorname{ergy}(\varepsilon)$ increases dramatically while the interfacial friction angle $(\psi)$ decreases monotonously, see Fig. 6 and Fig. 10. The results are shown in Fig. 11 in terms of average tangential force component as a function of the depth of cut. Tests carried out at back rake greater than $80^{\circ}$ are accompanied by clear visual evidence of damage on the rock surface (Fig. 12a and Fig. 12b); this damage affects the effective strength of the material at the bottom of the groove and therefore the results (force measurement) of the subsequent test (carried in the same groove), leading to the strength of the rock being underestimated. As successive tests are carried out with increasing depth of cut, such behavior results in the linear fit run on the representative points in a force-depth of cut diagram 
to be characterized by a lower slope and a larger intercept. Consequently, data were interpreted using only the results of tests performed at very shallow depth of cut and imposing a zero intercept (as linear fits run on points pertaining to tests carried out at smaller rake angles yield a near zero intercept).

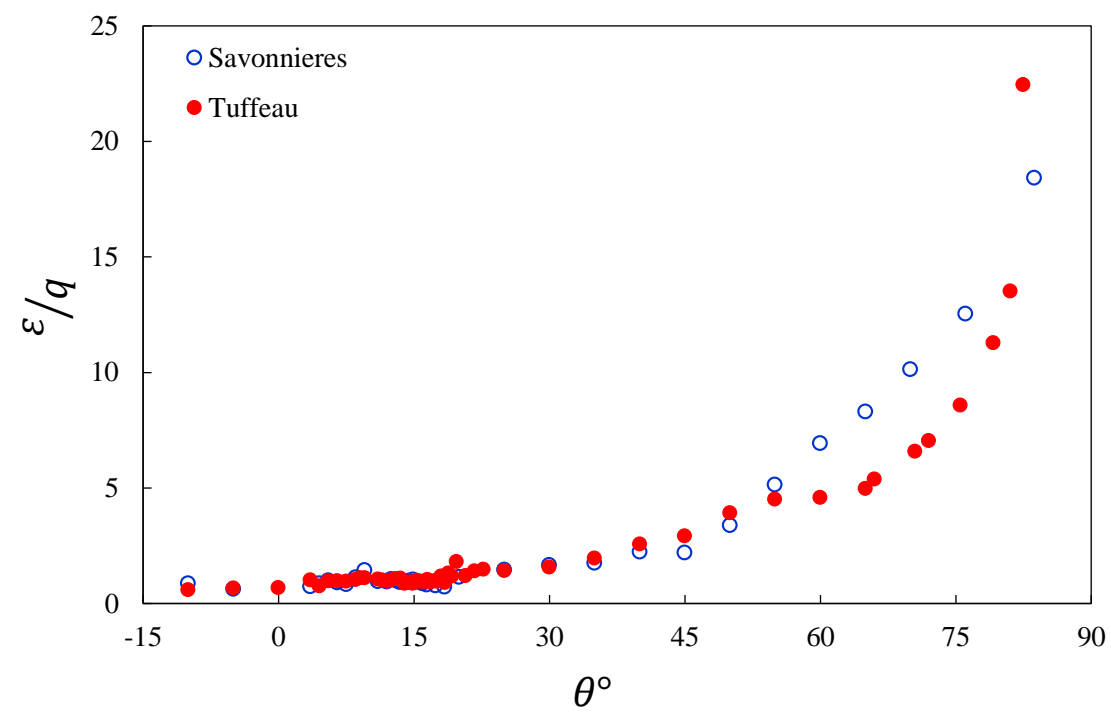

Figure 10: Scaled intrinsic specific energy $\left(\frac{\varepsilon}{q}\right)$ against back rake angle $(\theta)$. Tests performed with PDC sharp cutter on Tuffeau and Savonnieres limestones. 


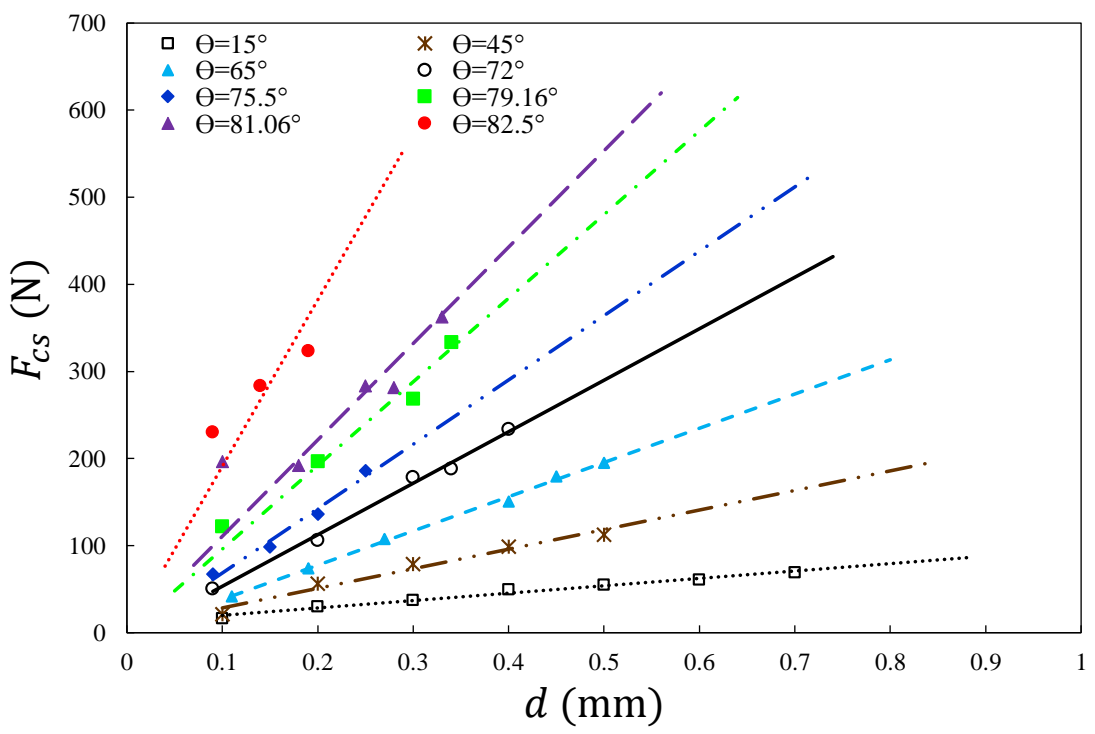

Figure 11: Evolution of tangential component of the cutting force in terms of depth of cut for various back rake angles. Tests conducted on Tuffeau limestone. 


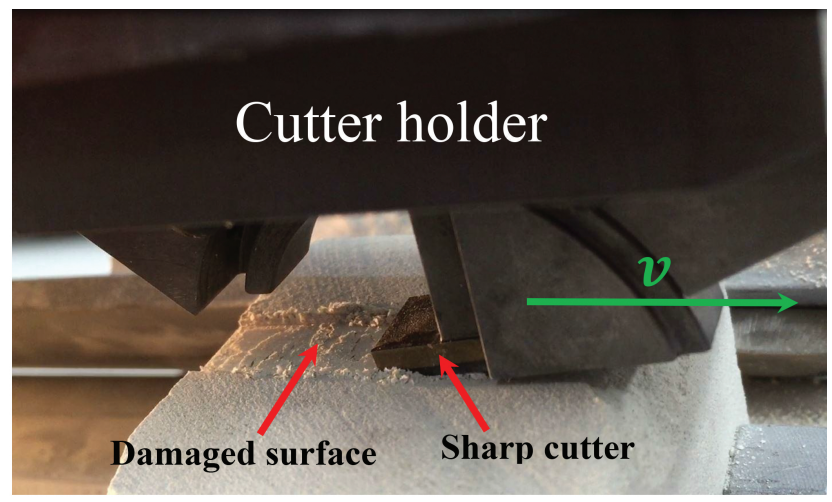

(a)

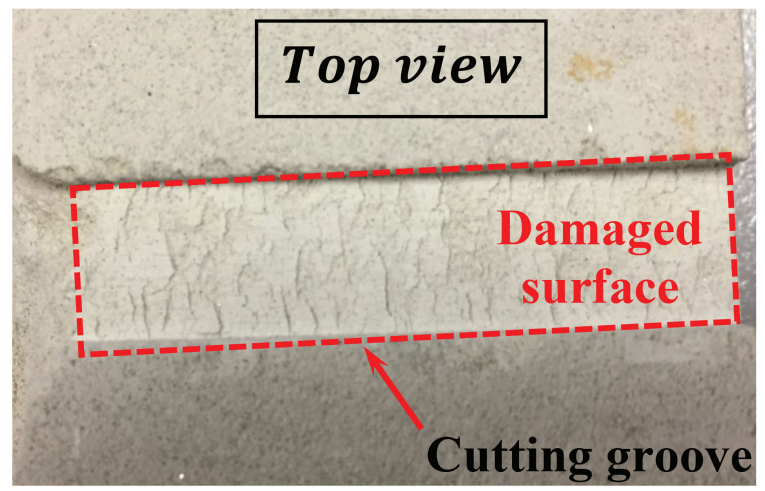

(b)

Figure 12: Evidence of damage taking place at the bottom of the groove during a cutting test at large back rage angle. Tuffeau limestone, sharp cutter at $\theta=79.16^{\circ}(a)$ during the cutting test, and $(b)$ after the cuttings were brushed away from the surface.

Cutting tests on Tuffeau limestone were carried out with a blunt cutter at three different inclination angles of the wear flat $\beta$ (the angle between the wear flat surface and the direction of cutting tool velocity vector $\boldsymbol{v}$ ) corresponding to 220 effective back rake angle $\left(\theta=\theta_{1}=75.5^{\circ}, 79.16^{\circ}\right.$ and $\left.82.5^{\circ}\right)$. Cutting tests with the blunt cutter were conducted at small enough depth of cut $(d=0.09 \mathrm{~mm}<$ $\ell \sin \beta$, with $\ell=1 \mathrm{~mm}$ ) so that only the wear flat surface was in contact with the rock sample, see Fig 13 . The procedure followed to set the wear flat back rake angle and run the tests is detailed in Ref. [25]. 
The results shown in Fig. 14 indicate that the forces acting on the blunt tool are found much smaller than the ones recorded on the sharp tool. One possible explanation is that the cutting face of the blunt tool being less inclined offers more relief for the flow of failed material, leading to a less contained flow and thus lower force (Fig. 13). These results strongly suggest that the cutting action of a wear flat surface on a cutter cannot be simply modelled as a cutting face inclined with a pronounced back rake angle.

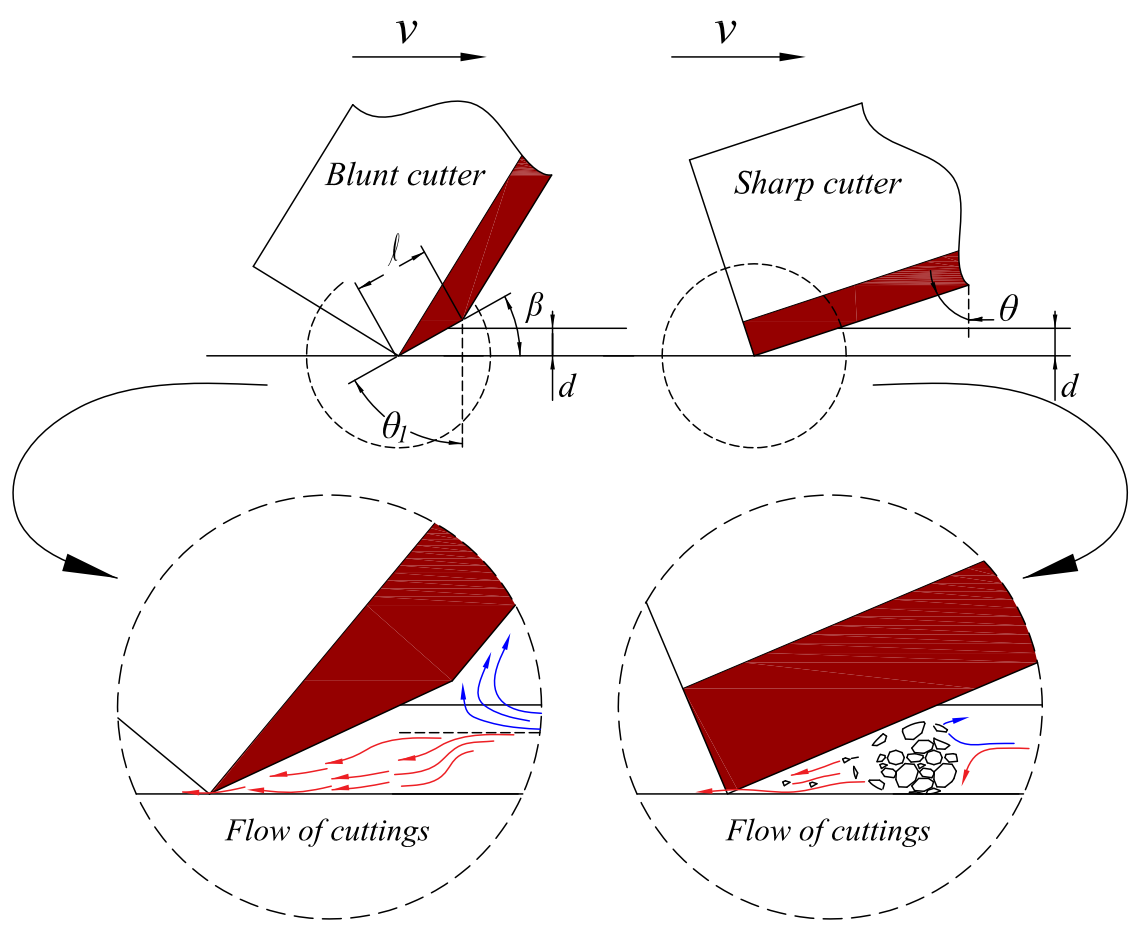

Figure 13: Schematic of a sharp and a blunt cutter for cutting test at very large back rake angles. 


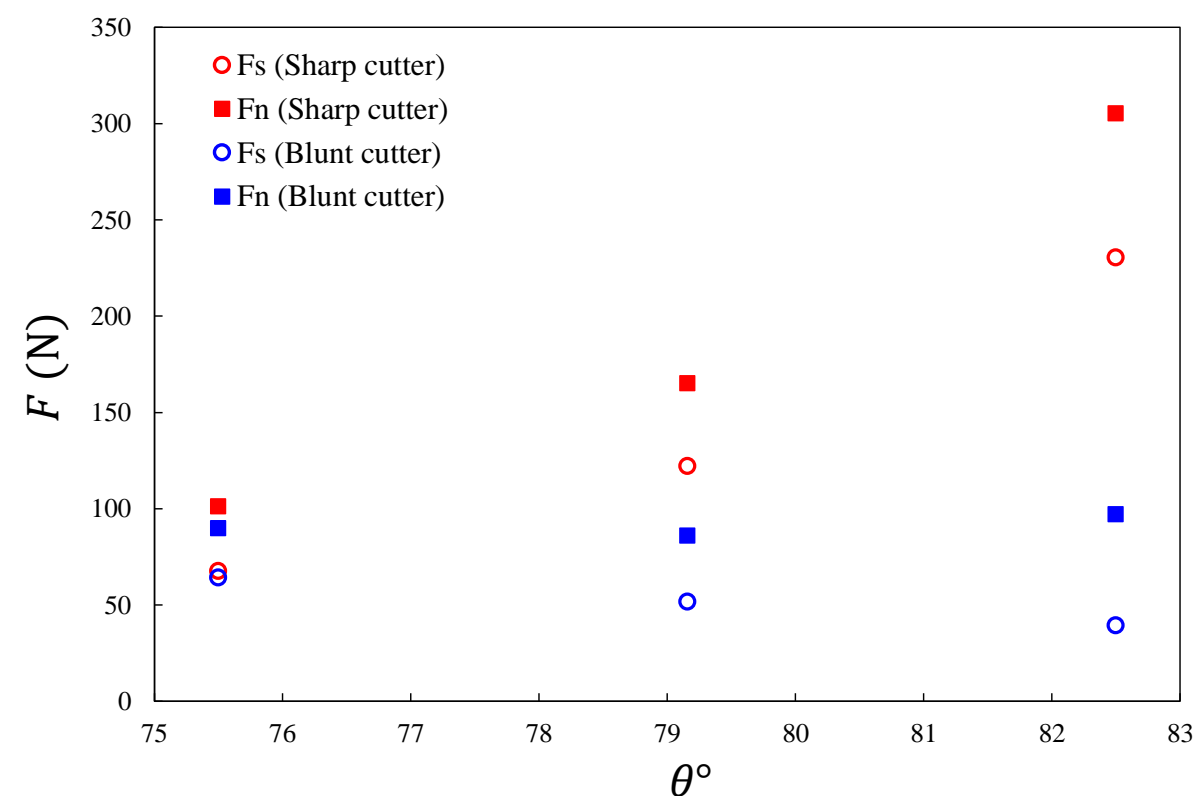

Figure 14: Cutting force components as a function of the back rake angle for tests carried out with a sharp and a blunt cutter at $d=0.09 \mathrm{~mm}$ in Tuffeau limestone.

\section{Conclusion}

A series of cutting experiments were conducted with a sharp cutter (with a width of $10 \mathrm{~mm}$ ) at various back rake angles $(\theta)$ varying from $-10^{\circ}$ to $85^{\circ}$, in the ductile regime of failure. The current results confirm previous results [22]: $(i)$ the intrinsic specific energy $(\varepsilon)$ increases steadily with the back rake angle, $(i i) \varepsilon$ is found to be very well correlated with the rock uni-axial compressive strength $(q)$ for back rake angles between $5^{\circ}$ and $20^{\circ}$ (results obtained for thirteen sedimentary rock materials), (iii) the inclination $\psi$ of the cutting force with respect to the normal to the cutter face decreases steadily with increasing back rake angle (results obtained for five quarry sedimentary rocks) confirming that $\psi$ is not controlled by a uniform frictional process along the cutting face. Beyond extending previous results to a wider range of rock materials, the current work 
has shown that tests carried out with a back rake angle larger than 75 degrees

${ }_{245}\left(\theta>75^{\circ}\right)$ lead to very pronounced damage of the rock surface for a depth of cut larger than $0.20 \mathrm{~mm}$. Finally, results show that the cutting response of a wear flat surface on a blunt cutting tool cannot be simply modelled as the limit case of the cutting response of a sharp tool at very large back rake angle. This has important consequence for modelling the response of chamfered cutters commonly used on PDC bits.

\section{Acknowledgment}

The first author would like to thank Joel Sarout and Jeremie Dautriat from CSIRO, Perth, Australia for granting access to Rock Mechanics Testing laboratory, research facilities and rock samples. The first author would like also

\section{Bibliography}

265

[1] L. Gerbaud, S. Menand, H. Sellami, PDC bits: All comes from the cutter rock interaction, IADC/SPE Drilling Conference, 21-23 February, Miami, Florida, USA, 2006.

[2] F. Bellin, A. Dourfaye, W. King, M. Thigpen, The current state of PDC bit technology, World oil 231 (9). 
[11] T. Richard, F. Dagrain, E. Poyol, E. Detournay, Rock strength determination from scratch tests, Engineering Geology 147-148 (2012) 91-100. 
[12] T. Richard, Determination of rock strength from cutting tests, M. Sc Thesis, Faculty of the Graduate School of the University of Minnesota, Minneapolis, Minnesota, U.S.A. (1999).

[13] H. Huang, E. Detournay, Intrinsic length scales in tool-rock interaction, ASCE International Journal of Geomechanics 8 (1) (2008) 39-44.

[14] Y. Zhou, J. S. Lin, On the critical failure mode transition depth for rock cutting, International Journal of Rock Mechanics and Mining Sciences 62 (2013) 131-137.

[15] W. Liu, X. Zhu, J. Jing, The analysis of ductile-brittle failure mode transition in rock cutting, Journal of Petroleum Science and Engineering 163 (2018) $311-319$.

[16] R. Teale, The concept of specific energy in rock drilling, International Journal of Rock Mechanics and Mining Sciences \& Geomechanics Abstracts 2 (1) (1965) 57-73.

[17] T. Richard, E. Detournay, A. Drescher, P. Nicodeme, D. Fourmaintraux, The scratch test as a means to measure strength of sedimentary rocks, no. SPE 47196, SPE/ISRM Eurock 98, Society of Petroleum Engineers, Trondheim, Norway, 1998, pp. 1-8.

[18] F. Dagrain, E. Poyol, T. Richard, Strength logging of geomaterials from scratch tests, EUROCK 2004 and 53rd Geomechanics Colloquium, Salsbourg, Austria, 2004.

[19] J. A. Mendoza, I. K. Gamwo, W. Zhang, J. S. Lin, Discrete element modeling of rock cutting using crushable particles, no. ARMA 10-232, 44th US Rock Mechanics Symposium and 5th U.S.-Canada Rock Mechanics Symposium, American Rock Mechanics Association, Salt Lake City, UT, U.S.A., 2010, pp. $1-7$.

[20] M. Theodoridou, F. Dagrain, I. Ioannou, Micro-destructive cutting techniques for the characterization of natural limestone, International Journal 
of Rock Mechanics and Mining Sciences 76 (Supplement C) (2015) 98 103.

[21] H. Munoz, A. Taheri, E. Chanda, Rock cutting characteristics on soft-tohard rocks under different cutter inclinations, International Journal of Rock Mechanics and Mining Sciences 87 (2016) 85-89.

[22] C. Coudyzer, T. Richard, Influence of the back and side rake angles in rock cutting, no. AADE-05-NTCE-75, AADE National Technical Conference and Exhibition, Houston, Texas, U.S.A., 2005, pp. 1-12.

[23] T. Richard, C. Coudyzer, S. Desmette, Influence of groove geometry and cutter inclination in rock cutting, 44th US Rock Mechanics Symposium and 5th US-Canada Rock Mechanics Symposium, American Rock Mechanics Association, 2010.

[24] B. Akbari, S. Miska, M. Yu, R. Rahmani, The effects of size, chamfer geometry, and back rake angle on frictional response of PDC cutters, no. 14-7458, 48th US Rock Mechanics / Geomechanics Symposium held in Minneapolis, MN, USA, ARMA, 2014.

[25] I. Rostam Sowlat, Effect of cutter and rock properties on the frictional contact in rock cutting with blunt tools, Ph.D. thesis, Curtin University (2017).

[26] S. Doshvarpassand, T. Richard, M. Mostofi, Effect of groove geometry and cutting edge in rock cutting, Journal of Petroleum Science and Engineering $151(2017) 1-12$.

[27] P. L. Menezes, Influence of friction and rake angle on the formation of built-up edge during the rock cutting process, International Journal of Rock Mechanics and Mining Sciences 88 (2016) 175 - 182. 


\section{Appendix A. Drawings of the sharp cutters}
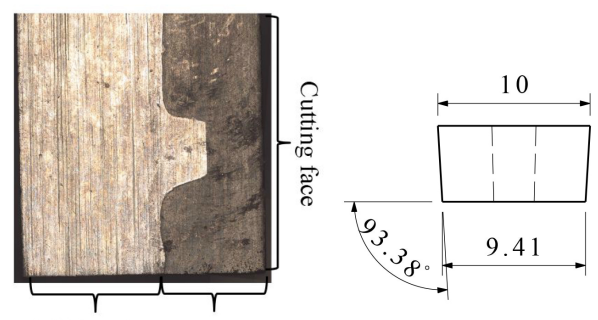

(a)

Carbide section PDC section

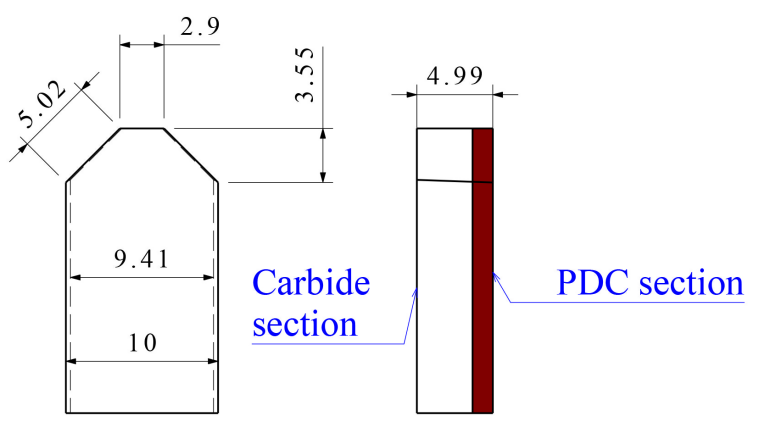

PDC section
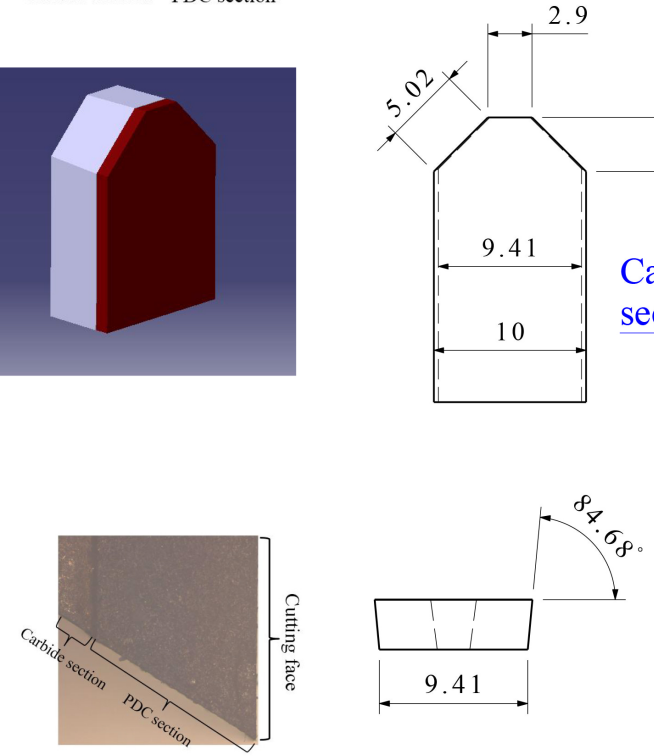

(b)
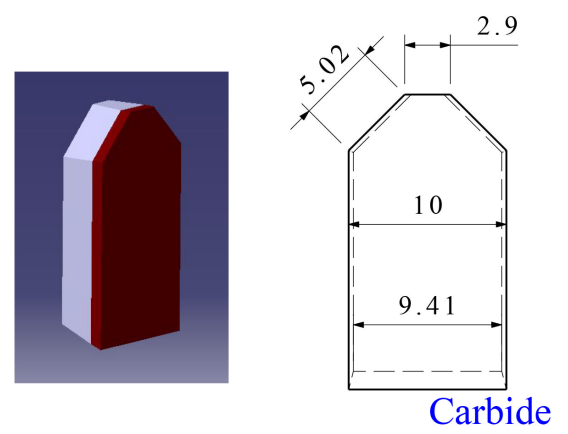

section

Figure A.1: Drawings and pictures of $(a)$ a standard sharp cutter and (b) a sharp cutter used for zero and negative back rake angles. 